\title{
TEACHING BIOCHEMISTRY USING EDUCATIONAL GAMES AND GAMIFICATION STRATEGIES
}

\author{
Yuri Rafael de Oliveira Silva ${ }^{1}$, Armando Maciel Toda², Luciana Pereira Xavier ${ }^{1}$ \\ 1 Universidade Feral do Pará, Faculdade de Biotecnologia-ICB (Pará, Brasil), 2Universidade de São Paulo, Instituto \\ de Ciências Matemáticas e Computação (São Paulo, Brasil)
}

Supported by: PROINT-UFPA, FAPESPA

INTRODUCTION: Biotechnology is a new bachelor degree in UFPA, and has been stablished with excellency in the state of Pará. However, there is the need to promote comprehension and learning in Biochemistry, as well as interdisciplinarity, that is an essential part of biotechnology. OBJECTIVES: To increase learning and interdisciplinarity, educational games were used as tools. The students were instigated to develop educational games in different topics of energy metabolism. MATERIALS AND METHODS: The games were developed to be used in any teaching environment, since they were made with low-cost and accessible materials. This strategy was applied in three semesters in different Biochemistry classes, between 2012 and 2014. The best games in each class were used in following semesters. DISCUSSION AND RESULTS: Since the first semester, the failing rates dropped $15 \%$ compared to the previous semester, in which educational games were not used. An increase in learning (by observation) could be noticed, including comprehension of metabolic pathways and their conections. Twenty games were developed in three semesters, and four of them are still being improved and used in other classes. The participant students answered a questionnaire, in which $47 \%$ defined the games as "Relaxing and Instigating", 33\% said the games "Accomplished their didactic and educational role" and 54\% said they would recommend the use of these games as a reviewing activity. At the moment, another approach is being used to teach Biochemistry - Gamification, which uses elements found in games, as conflict, cooperation, rules and fun, to improve students' motivation and engagement. CONCLUSION: As a partial result, there was greater in-class interest and engagement, better comprehension of the course content and the activities gave the students the opportunity to work in groups, to think critically about the themes and to develop opinions based on interdisciplinar and formal knowledge.

Keywords: Educational games; Gamification; Biotechnology 